\title{
Online Learning and Self-Regulation Strategies: Learning Guides Matter
}

\author{
Maher S. Al-Hawamleh $\left(D,{ }^{1}\right.$ Asmaa F. Alazemi $\left(D,{ }^{2}\right.$ Dina A. H. Al-Jamal $\left(D,{ }^{3}\right.$ \\ Samar Al Shdaifat ${ }^{(D},{ }^{4}$ and Zeynab Rezaei Gashti ${ }^{5}{ }^{5}$ \\ ${ }^{1}$ Curricula \& Instruction Dept., Al al-Bayt University, Mafraq, Jordan \\ ${ }^{2}$ The Public Authority for Applied Education and Training, Kuwait, Kuwait \\ ${ }^{3}$ Curricula \& Instruction Dept., Yarmouk University, Irbid, Jordan \\ ${ }^{4}$ RTI International, Zarqa, Jordan \\ ${ }^{5}$ Department of Literature and Foreign Languages, Islamic Azad University of Karaj, Karaj, Iran
}

Correspondence should be addressed to Dina A. H. Al-Jamal; deena.j@yu.edu.jo and Zeynab Rezaei Gashti; zeynabrg2010@gmail.com

Received 11 January 2022; Revised 15 January 2022; Accepted 18 January 2022; Published 31 January 2022

Academic Editor: Ehsan Namaziandost

Copyright (C) 2022 Maher S. Al-Hawamleh et al. This is an open access article distributed under the Creative Commons Attribution License, which permits unrestricted use, distribution, and reproduction in any medium, provided the original work is properly cited.

\begin{abstract}
For master's degree students, self-regulated learning research is limited, even though the number of online learners has exploded in recent years, especially after the international COVID-19 pandemic. This study investigated the effect of a self-regulated learning guide to help students act somewhat more autonomously. To collect the data, a self-regulated learning guide along with a questionnaire and an achievement test was used. Forty master's degree students (20 students in each group) participated in this study; they were distributed into two groups (A and B). Group A attended online classes with their instructor, while Group B students attended online classes and received the learning guide to help them pinpoint specific strategies in the given learning context. This paper presents the results obtained from the questionnaire distributed to the students and their end-of-course test results by comparing estimated with the actual performance scores. The study concluded that providing students with a learning guide helps them regulate their learning effectively.
\end{abstract}

\section{Introduction}

In this age, technology is developing rapidly at all levels of university student's life. However, the latter is found in a situation of relative passivity that leaves little room for initiative [1]. The student has the role of the receiver during most of the online classes. Overall, he must acquire the teacher's input and revise it to pass the exam. In this way, learning usually stops when one graduates from college. However, one of the significant functions of education is the development of learning skills in the student throughout one's working life. Thus, after graduation from university, he must learn other vital informal skills [2]. Researchers have clearly shown that students who are self-regulated in their learning have the ability to self-determine strategies for learning to perform their tasks in an increasingly satisfying manner [3-6].

Self-regulation is not an innate characteristic of the individual. It is a learning process that is acquired and must be continuously nourished and reinforced. For this reason, many have attempted to find teaching methods or models of self-regulation $[7,8]$. Furthermore, there is a growing need for lifelong learning that transcends the barriers of educational institutions, but as the demand grows, the challenge becomes more remarkable and more significant for the public sector [9-11]. Additionally, educational psychology adds that combining multiple learning channels accentuates this challenge. In this context, e-learning offers unprecedented implementation of this principle [12]. Indeed, e-learning makes it possible to combine the advantages of 
personalization, tailoring, and limiting. However, it represents a significant change in the working habits of learners and instructors.

\section{Purpose and Context}

This study is about an experiment carried out as part of a research methods course taught to university students at the college of education at $\mathrm{Al}$ Ain University. During the coronavirus pandemic, university master courses were delivered online rather than through traditional face-to-face lectures. Every course continues one semester where each meeting lasts for three hours, once a week. In order to measure the degree of students' self-regulation and autonomousity, a Learning Guide for the Self-Regulated Learner was developed to assess the degree of motivation of the students vis-à-vis the online course and the developed guide. This course has two roles: the first is to allow the students to practice online learning, and the second is to support their autonomy in learning. After the definition of self-regulation, the Learning Guide for the Self-Regulated Learner was explained to the targeted students.

\section{Literature Review}

3.1. Self-Regulated Learning. Self-regulated learning is defined by Zimmerman and Schunk [13] as an active and constructive process by which learners set their learning goals and exercise monitoring and control over their knowledge, motivations, and behaviors. They are guided in this process by their goals and learning environments. In addition, the self-regulated learner focuses on mastering academic tasks, such as reading grades, preparing for lessons, managing time and meeting deadlines, and improving skills and understanding. He is not concerned with competing with classmates and evaluating himself about others [14-16].

Self-regulation is about approaching a learning task with confidence, diligence, and resourcefulness. The learner is then aware of his degree of mastery and knowledge of a studied object. He searches for the information he needs and assimilates it. He can find a way to succeed when faced with obstacles such as poor study conditions, teachers who cannot get the point across, and the unavailability of books on the subject [17]. Self-regulation assumes that the active learner who controls their learning performs better than others [18-20]. In order to measure the degree to which students are inclined to become more self-regulated, a SelfRegulated Learners' Guide was developed by the researchers, which they detail in the next section.

3.2. Self-Regulated Learners' Guide. Researchers have claimed that effective learning strategies play an essential role in developing student motivation [21-23]. Self-regulated students apply different learning strategies appropriate to specific tasks [24-26]. These strategies should be connected and linked, as much as possible, to real-world examples that can help students integrate their learning with a possible and achievable future.
In developing the Self-Regulated Learners' Guide, the goal was to direct and help students self-regulate their learning. Each student could adopt the right strategies and even learn from those strategies to find better ones. However, what works for one student does not necessarily work for another, and what works for one student at one time may not necessarily work for the same student at another time. Therefore, this guide was designed with guidelines and suggested strategies to help students master academic tasks and improve their skills and understanding. The Self-Regulated Learners' Guide is divided into six main sections: goal setting, planning and time management, learning strategies, self-monitoring, strategies for taking the test, and selfreflection.

3.3. Goal Setting. Setting goals allows the learner to define the range of options and the tools to be used. Therefore, the student can save considerable time starting and completing his learning. In addition, he can judge his progress and whether he has achieved his goal or not because he knows exactly where he wants to go [27]. It is necessary to set appropriate and achievable goals. These must come from the individual himself and not from another person. In addition, the objectives should focus on learning and mastering one aspect and not on performance [28]. Indeed, students who set the goal of acquiring knowledge in a subject are more motivated and better able to overcome their frustrations than those who set themselves the purpose of being top of the class.

The goals, thus, set a more practical challenge for the learner and positively affect the student's self-regulation [29]. There are two types of goals, namely, long-term goals and short-term goals. Achieving long-term goals requires months or even a semester (e.g., completing course chapters), while short-term goals require a few days or weeks (e.g., giving more time to homework, the house) [30].

3.4. Planning and Time Management. The learner must manage their time and resources with adequate planning and control to prioritize, overcome frustration, and persist through task completion. This planning saves learners time and energy, but it requires distinguishing between what is important and what is not [29]. In practice, the student will have to make a plan from his short-term goals, set in advance, to develop a list of steps to be taken. These steps will be accompanied by a list of potential problems and possibilities to resolve them.

3.5. Learning Strategies. Learning strategies can be defined as operations that an individual engaged in a training process performs to promote the acquisition of knowledge, skills, or attitudes [31-33]. These strategies refer to any technical activity or procedure used by learners to improve their understanding and performance in a learning task [34-36]. However, there are no effective strategies in all situations, but in a given context. In addition, the effectiveness of a strategy depends on its adaptability to the 
individual using it. In this study, strategies were grouped according to different types [37]:

(i) Organizational strategies to better organize oneself in one's learning work

(ii) Social strategies for learning from those around them and using their skills

(iii) Active learning strategies that prevent students from escaping or slacking off during their learning

(iv) Cognitive strategies allowing the student to better assimilate and memorize the revised information over the long term

3.6. Automaticity. It reflects students' commitment to performance. Of course, assessing the effectiveness of one's learning strategy is crucial. If retained and applied in a specific learning context, a strategy is deemed adequate. In other words, it would be a mistake to use a strategy, successful in a particular setting in all learning situations. On the other hand, it will be necessary to identify a set of practical strategies, each for a specific situation, to use them if a similar situation arises [38]. Self-monitoring is done continuously at each stage of learning. This is done concerning planning and meeting short-term goals. Thus, reaching the short-term goals induces the achievement of the long-term goal.

3.7. Strategies for Taking Tests. It is essential to point out at this level that good preparation for a test presupposes good time management, good note-taking, and a regular review of the concepts studied. A revision results in a weekly or even daily review of the course. A review of the test is also necessary to distinguish between the concepts mastered and those that are less mastered to memorize them definitively [39].

3.8. Self-Reflection. Self-judgment and self-reaction in learning are crucial to self-regulation. The student should assess the degree of achievement of his preset learning objectives and know how to react to failure. Indeed, failure is a significant obstacle to self-regulated learning. Students, therefore, tend to doubt their abilities and become discouraged before reaching their goals. However, they fail to consider that overcoming failure is more important than failure per se [29].

Few empirical studies have looked into master's degree students' self-regulation strategies. In this online learning study, learners' guides were employed with complicated and straightforward cognitive methods. As a result, the current research has innovative features such as identifying learners' behavior toward site links, perspectives on-site connections, and self-regulation characteristics such as self-estimated and self-esteem.

3.9. Research Methods Course. Among the courses taught to master degree students is research methods; it is an introductory course that offers students the gears required to ask and answer queries and evaluate and build knowledge. The interest of such a course is to enable future graduates to understand better how to research so that they can more easily use the research methods to solve educational problems. The objective of this course is, on the one hand, to familiarize students with the use of online learning and, on the other hand, to help them to start learning research methods. The student will thus have to learn to find the solution of a problem using research type form and learn how to design research papers in a structured manner. In addition, e-learning will allow the students to have a source of learning other than the tutor, which would encourage them to carry out their research tasks with their strategies to become more autonomous and more self-regulated.

The online research method course consists of the following links:

(i) Theoretical: this is a link to the chapters of the course

(ii) Exercises: this is a link to classic exercises, thereby going through the course with statements and corrections

(iii) Simulation: this is a link that offers the students simulations of the processing of basic research terminologies, such as research problem, and research design

(iv) Multiple Choice Questions: this is a link to exercises in multiple-choice questions that allow the students to check their knowledge

(v) Games: this is a link to an educational game that allows the students to test their research knowledge

(vi) Downloads: this is a link that offers the students the download of parts of the course and exercises

It was intended to measure the attitude and motivation of students towards each of the parts presented by the links of the online course to shed more light on the level of selfregulation of students, on the one hand, and their preferences about links, on the other hand.

\section{Methods}

4.1. Sampling and Procedures. A set of 40 postgraduate students enrolled in a research methods course at Al Ain University, UEA. There have been 20 males and 20 females, with an average age of 25 . All of the participants were from the Faculty of Education. However, they were from various majors in Arabic, English, math, and science. All the participants took at least one face-to-face semester instruction.

What is important to measure is the degree to which the characteristics of self-regulation are present in students. For this, the online course, on the one hand, and the SelfRegulated Learners' Guide were used simultaneously. Two types of samples (20 students per group) were chosen randomly; Group A is the sample of students following the online classes to whom the e-learning portal was consulted in parallel with their courses, and Group B is the sample of 
students pursuing the course online and to whom the SelfRegulated Learners' Guide was given.

Two types of comparisons were considered here to measure student self-regulation strategies and the influence of the Self-Regulated Learners' Guide. The reason behind the two groups' choice was based on the fact that the students of the two samples had to take the same classic course with the same instructor and had to take the same test so that we could compare their final marks. The instructor had to teach the course regardless of the samples and give all the students the same test.

4.2. The Survey. At the end of the research methods course at the college of education, a questionnaire for the two samples was distributed. This questionnaire is made up of three distinct parts. Motivation is often seen as the engine of learning. Therefore, the first part of the questionnaire was devoted to measuring motivation towards the course and the Self-Regulated Learners' Guide.

Moreover, since the type of motivation may differ from one student to another, three forms of motivation were distinguished: motivation linked to the student's interest in the subject, such as the need to improve, a motivation related to a specific power relationship on the part of the course structure, such as the fact that it is imposed, and a motivation linked to the student's personality, such as curiosity. This distinction is essential because it can qualify certain students' personality traits; thereby, an indication index of the student's self-regulation is given.

In the second part, we wanted to measure the attitude and motivation of students towards the online course as a source of learning. In the third part, the questionnaire aims to measure the degree of self-regulation of students and their degree of self-esteem by measuring their degree of confidence in taking the test. Finally, through the questionnaire, the usefulness of the guide for courses was measured and its possible influence on the further learning of students after graduation.

In addition, the students of the two groups took the same test prepared by their instructor. The questionnaire was distributed and completed by the students before the test, because each student had to indicate an interval of their estimated grade among the intervals $[0,10],[10,14]$, and $[14$, 20]. The percentages of these intervals will be compared with those of the effective score intervals after the test has been taken.

4.3. Findings. Two initial findings were made: on the one hand, online learning and, on the other hand, learner selfregulation.

4.4. Preliminary Findings. $75 \%$ of Group A students attended the online classes, while $62.9 \%$ said they did not attend. Those who did not attend the online class said they intended to. Here, there are three types of motivation for attending online classes. Specifically, 33.3\% felt they attended for improvement, $5.6 \%$ because it is imposed, and $61.1 \%$ out of curiosity. $27.3 \%$ of Group B students consulted the guide. $76 \%$ replied that they intended to read it. Concerning the three types of motivation, $19.2 \%$ of the students intended to improve. $0 \%$ of the students said they had read it because it is imposed, while $80.8 \%$ stated they had read it out of curiosity.

As the percentage of students who preferred to attend the online course $(75 \%)$ is much higher than that of students who have preferred to attend the online session and read the Self-Regulated Learners' Guide distributed to them (27.3\%), this led us to think that one of the possible suppositions is that the students took advantage of the learning byline, namely, the liberty about place and time.

It was also observed that students' motivation for attending the online site and reading the guide is essentially linked to their curiosity (61.1\% for Group A and $80.8 \%$ for Group B) and not that the course regulations impose it. This has led us to suggest that students become more autonomous and self-regulated.

4.5. Results Compared to the Online Course. First, a distinction between the course links visited, the links manipulated, and the links preferred by the students was made. A visited link is a link that a student has clicked without too much time, quickly switching to another link. A manipulated link is a link that a student has clicked on, using their corresponding page to perform activities such as reading the course text for the "Theoretical" link, keenness on the exercises for the "Exercises" link, the answer to the "Multiple Choice Question" link, playing the simulations and games for the "Simulations" and "Game" links and, finally, the downloading of the parts of the course for the "Downloads" link. A favorite link is a link that the student who visited it liked.

When answering the questionnaire, the student had to check off, among the types of links, those they only visited, those they manipulated, and those they preferred. We found that it was easier to do a manual census of the responses, as each student could tick several links simultaneously. Table 1 contains the measured percentages of students who checked the different links they visited, manipulated, and preferred, showing student behavior towards the different links on the online site.

It is noticed that the highest percentages are those of the "Theoretical" and "Exercises" links. This suggests that the students are very connected to their classroom course and that by looking at the site, they have looked for some resemblance to it. Therefore, offering them the links of "Simulations" and "Educational Games" presents a change for them from their usual learning. However, although the "Simulations," "Multiple Choice Question," and "Game" links represent low percentages, we can see that most of the students who visited these links liked them, even if they did not manipulate them.

Indeed, of the $21.05 \%$ who visited the "Simulations" link, $15.78 \%$ liked it. In addition, all the students who visited the "Multiple Choice Question" and "Game" links found them pleasant. This suggests that if students find themselves 
TABle 1: Behavior towards site links (in percentage).

\begin{tabular}{lcccccc}
\hline Connections & Theoretical & Exercises & Simulations & Questions & Games & Downloads \\
\hline Visited & 94,73 & 78,94 & 21,05 & 15,78 & 26,31 & 15,78 \\
Manipulated & 78,94 & 42,1 & 10,52 & 15,78 & 10,52 & 10,52 \\
Preferred & 68,42 & 36,84 & 15,78 & 15,78 & 26,31 & 0 \\
\hline
\end{tabular}

motivated in their course to visit all of these links, they might appreciate them. On the other hand, the "Downloads" link was visited by $15.78 \%$ of the students, but nobody liked it. This link allows you to keep a copy of the theoretical course; however, students would prefer their teacher's course, thinking that the test would be based on the latter rather than the online course.

In addition, the opinion of the students regarding the different links was one of the study's concerns. So, on a scale of 1 to 5, 1 represents "too little" and 5 "a lot" for each link. The students participating in the study were asked how much these sections motivated them to explore the site even more, how much these parts were advantageous to their course, and how they could help them with their final test. We noted the percentages of the highest ticked scales for each link in Table 2.

The first general remark, from Table 2, is that the links "Theoretical" and "Exercises" represent the highest percentages with an average scale of 3 for most of the answers. The majority of students think that these links motivate them to explore the rest of the site more, give them something more than their classroom course, and help them with their tests. This confirms the finding found in Table 1. The "Multiple Choice Questions" link represents very close percentages with scales 3 and 4 . The multiple choice questions can reflect the teacher's course where the students must choose the exact answers from statements or definitions.

The "Simulations" link represents $7.5 \%$, thereby equal to scales 2 and 4 . The students do not all agree on whether this link motivates "a little" or "a lot" to explore the rest of the site; it is an entirely new educational tool for them. On the other hand, their opinion is more precise for the following two questions: only $10 \%$ of students believe that this link brings added value or helps with their final test. Indeed, during the test, students will have a hard time imagining the application of the site's simulations in their answers.

The "Game" link motivates students a lot to explore the rest of the site, but it was noticed that it is pretty difficult for them to assess the added value that educational games bring and how they can help them in the success of the final test, since the scales used are "too little" and "a little," that is, 1 and 2 .

Finally, the "Downloads" link remains the one that least motivates students. They are not interested in keeping a copy of parts of the course. They would prefer to revise from their instructor's classes for their final test to better guarantee their grades.

In this context of online learning, the percentage of students who have previously taken an online course is considered in this study. Likewise, their motivation for repeating the experience was felt important to be assessed.
For the majority of the students of the two groups, namely, $70 \%$, this contact with an online site represents the first experience of this kind. Thus, they answered the questions using a scale of 1 to 5 , where 1 represents "not at all" and 5 "very much." It is noted that the percentages of the highest ticked scales in Table 3 reflected their self-regulation.

The average of the percentages in the table represents $32 \%$, with scales between 2 and 4 . These percentages represent students who think (scale 3) that they are moderately able to set achievable goals, who are highly motivated (scale 4) to better master the course, who think on average (scale 3) that they can manage their time, who can moderately (scale 3) have social strategies in their learning, and who can moderately (scale 3 ) rearrange the examples in the guide to their own experiences which may weakly (scale 2) have cognitive strategies and self-control.

The fact that the percentage values do not represent significant differences indicates that the sample is relatively homogeneous. On the other hand, the scales chosen reflect an attitude that is uncertain, even indifferent. This indicates that the students still lack confidence and must learn to be more self-regulated.

It would be interesting to improve the guide by creating an interactive site for the independent learner, which would replace the paper guide in the experiment and better motivate students to enhance their autonomy and selfregulation.

4.6. Results after the Test. It is helpful to remember that by comparing students' grades, the idea here is not to check whether their grades are improved from sample to sample but rather to detect specific characteristics in students that might give us a clue about their self-regulation. In the test given by the instructor, the two groups of students are required to solve three exercises presented as statements and requiring the writing of a research problem, figure out the research design, and identify the themes per a specific research title. In addition, the rating adopted by the instructor in all courses is the rating out of 20 , where 10 is an average mark. Thus, three intervals were used to record the percentages of students' marks, $[0,10]$, representing students who are below average, $[10,14]$, representing average students, and $[14,20]$, representing good students.

Table 4 presents the percentages of the estimated and actual scores for the two samples. In calculating these percentages, an interest in the following types of comparisons was maintained.

The first is the comparison of the estimated percentages estimated and actual percentages for the two samples; this will allow us to indicate the ability of the students to selfestimate their grade interval. The second is the comparison 
TABLE 2: Student opinions on the links on the site.

\begin{tabular}{lccccccc}
\hline & & Theoretical & Exercises & Simulations & Questions & Games & Downloads \\
\hline \multirow{2}{*}{ Motivation to explore more of the site } & $\%$ & 27,5 & 17,5 & 7,5 & 12,5 & 10 & 12,5 \\
& Scale & 3 & 3 & $2 \& 4$ & 3 & 4 & 1 \\
\hline \multirow{2}{*}{ Added value } & $\%$ & 15 & 15 & 10 & 15 & 10 & 10 \\
& Scale & 3 & 2 & 2 & $1 \% 2$ & $1 \& 2$ \\
\hline \multirow{2}{*}{ Help for the final test } & $\%$ & 22,5 & 17,5 & 10 & 10 & 17,5 & 12,5 \\
& Scale & 3 & 4 & 1 & 4 & 1 \\
\hline
\end{tabular}

TABLE 3: Characteristics of self-regulation in students.

\begin{tabular}{lcc}
\hline Characteristics of self-regulation & Maximum percentage & Scale \\
\hline Set attainable goals & 32,5 & 3 \\
Motivation for the desire for mastery & 40 & 4 \\
Planifier et gérer son temps & 30 & 3 \\
Have social strategies & 30 & 3 \\
Transfer the examples to one's own experience & 30 & 3 \\
Have cognitive strategies & 32,5 & 2 \\
Self-control & 30 & 2 \\
\hline
\end{tabular}

TABle 4: Percentages of estimated and actual scores according to the two samples.

\begin{tabular}{ccccc}
\hline \multicolumn{2}{c}{ Note intervals } & {$[0,10]$} & {$[10,14]$} & {$[14,20]$} \\
\hline \multirow{2}{*}{ Group A } & Estimated & 50 & 33,4 & 16,6 \\
& Actual & 70 & 20 & 10 \\
\hline \multirow{2}{*}{ Group B } & Estimated & 50 & 41,7 & 8,3 \\
& Actual & 80 & 10 & 10 \\
\hline
\end{tabular}

of the estimated percentages of the different intervals of the two samples; this will allow us to indicate the degree of selfesteem of the students. The third is the comparison of the actual percentages of the different intervals of the two samples; this will allow us to see if, compared to compare the scores of Group A and Group B, there is an influence that is attributed use of the Self-Regulated Learners' Guide.

\section{Discussion and Conclusion}

5.1. Self-Estimate. Research has shown that the inability to judge one's skills leads to failure of self-regulation [40]. By comparing the estimated percentages of the different intervals, we notice that for Group A, the highest estimated percentage is $50 \%$ for the interval $[0,10]$, while the highest effective percentage is $70 \%$ for the interval $[0,10]$. This shows a poor ability to self-estimate one's grade interval among most students in this sample. We recall that the students of Group A took the classic course, by attending online classes, without access to the guide and that they, therefore, had no help. In contrast, most Group B students can self-estimate their grade interval, thus being more apt to become selfregulated in their learning.

5.2. Self-Esteem. According to research studies (e.g., [41-43]), low self-esteem leads the learner to set unsuccessful goals with fewer challenges in order to escape failure. On the other hand, high self-esteem leads the learner to face more challenges out of pride. Therefore, high self-esteem can be beneficial for self-regulation, given the challenges involved. Nevertheless, it can sometimes have harmful consequences. As this type of learner does not accept failure out of pride, he may encounter blocking situations that lead him to failure.

By comparing the percentages of the estimated intervals, it is noticed that half the students in Group A think they have their grades in the interval $[0,10]$. This represents average self-esteem. On the other hand, this estimate is similar for most Group B students, with 50\% estimating their grades in the range $[0,10]$. In Group B, self-esteem goes up relative to that of Group A students. Indeed, the majority of students (50\% and $41.7 \%)$ estimate their grades in the intervals $[0,10]$ and $[10,14]$, respectively. Therefore, it can be noticed that the guide seems to have contributed to the improvement of the students' self-esteem.

Specifically, augmenting transparency in affirming learning steps offers an effective learning experience for students. It is at times easy to remember that steps or details when didactic choices are clear. For instance, explain one way to inspire students to participate in their behavior towards site links. One possible explanation may be related to the course tutor who was explicit with students about their didactic choices. How will visited, manipulated, and preferred sites affect their learning? Why are theoretical, exercises, simulations, questions, and games that value their time and effort? Research by Maruyama et al. [42] suggests that views and perceptions powerfully impact students' selfesteem.

5.3. Influence of the Self-Regulated Learners' Guide. Looking at the percentages of students' actual marks in Table 4, it is noticed that those in Group A seem to be well distributed between the intervals. Scores are lower for Group B students and decline further for Group B. This is due, on the one hand, to the nature of the test, which is directly 
linked to the instructor's course and, on the other hand, to the students who did not know how to use the online site in a way to improve their level of mastery of the course and could not draw a stimulus from the suggestions and directives of the guide to find their learning and preparation strategies for the test. Therefore, it would be recommended to change the course system used with students for their teaching and assessment. Methods should help foster greater student autonomy and motivate them to diversify their learning resources.

In this study, with the emphasis on preparing learners to "think," learner guides helped the participants learn the content of the online course and helped them become selfregulated learners capable of solving research problems. This was delivered by the guides to develop their metacognitive strategies. Further, an online course with the type of explicitness defined earlier is one way to enable learners. By assisting them to appreciate learning options, learners feel like associates in the learning process. To this end, autonomous learning is created. Further, autonomous learning, as described by [27], allows learners to realize more about themselves and will help them to be self-regulated, lifetime learners.

Specific pedagogical implications may be presented in light of the current study's findings.

(i) Use the self-regulated learning guides to teach analytical skills to improve learners' comprehension and critical thinking skills at different levels

(ii) Design interactive materials based on the guides, transforming learners from dependent into independent readers

(iii) Use the guides in developing thinking skills for students with learning difficulties in the school stage

More importantly, using learning guides in online courses has three key cognitive, metacognitive, and motivational implications as follows:

(1) Teachers are advised to analyze task requirements, set productive goals, and select proper activities that are related to the learners' daily lives, such as, brainstorming discussion, brainstorming assignment, reciprocal questioning, or active learning techniques. Actually, learners will achieve successful performance if they focus on self-regulated learning guides components, such as cognitive skills and habits that are essential to encrypt, remember, and elicit facts and reason analytically.

(2) According to the learning guides metacognitive skills components, teachers can think of activities that focus on the integration and conceptualization of new topic. For example, learners can be asked to observe before passing any value judgment. That is, they form reasons behind their choices.

(3) Incorporating self-regulated learning guides into postgraduate programs could reduce students' anxiety and shyness. Thereby, learners will be inspired by them and it may contribute to a better understanding of the course components.
As a result of this study, it is observed that the students are still too attached to their online course with the instructor only, which affects their degree of self-regulation and autonomy. On the other hand, students prefer online meetings and following the Self-Regulated Learners' Guide; thereby, an improvement in students' self-esteem was evident. However, they could not use the right learning strategies to improve their grades.

In a future study, a plan to replicate the study by creating an interactive site for learning with a self-regulated guide may inspire and motivate students to improve their selfregulation and better adapt to online learning. Further, it is recommended that researchers investigate self-regulated learning guides across various disciplines at the university. It is also recommended to explore the effectiveness of using self-regulated learning guides in reducing learners' anxiety.

\section{Data Availability}

The data that support the findings of this study are available from the corresponding author upon reasonable request.

\section{Conflicts of Interest}

The authors declare no conflicts of interest.

\section{References}

[1] S. Kruikemeier, G. Van Noort, and R. Vliegenthart, "Unraveling the effects of active and passive forms of political Internet use: does it affect citizens" political involvement?" New Media \& Society, vol. 16, no. 6, pp. 903-920, 2014.

[2] B. J. Zimmerman, "Becoming a self-regulated learner: an overview," Theory Into Practice, vol. 41, no. 2, pp. 64-70, 2002.

[3] M. D. Hakel, "Learning that lasts," Psychological Science, vol. 12 , no. 5, pp. 433-434, 2001.

[4] C. Lai and H. Gwo-Jen, "Strategies for enhancing self-regulation in E-learning: a review of selected journal publications from 2010 to 2020," Interactive Learning Environments, 2021, In press.

[5] A. McCardle and A. F. Hadwin, "Using multiple, contextualized data sources to measure learner's perceptions of their self-regulated learning," Metacognition Learning, vol. 10, no. 1, pp. 43-75, 2015.

[6] S. Sahranavard, M. R. Miri, and H. Salehiniya, "The relationship between self-regulation and educational performance in students," Journal of Education and Health Promotion, vol. 7, pp. 1-5, 2018.

[7] K. R. Harris, "Developing self-regulated learners: the role of private speech and self-instructions," Educational Psychologist, vol. 25, no. 1, pp. 35-49, 1990.

[8] T. Schmidt, "Developing self-regulation does not equal selfinstructional training: reply to Braswell," The ADHD Report, vol. 6, no. 2, pp. 7-11, 1998.

[9] J. S. Avery, Space-age Science and Stone-Age Politics, Danish Pugwash Group, Copenhagen, Denmark, 2005.

[10] M. Y. Doo, C. J. Bonk, C. H. Shin, and B.-D. Woo, "Structural relationships among self-regulation, transactional distance, and learning engagement in a large university class using flipped learning," Asia Pacific Journal of Education, vol. 41, no. 3, pp. 609-625, 2021. 
[11] J. Visser, "Learning in a global society," in Handbook of Distance Education, M. G. Moore, Ed., pp. 635-648, Lawrence Erlbaum, Mahwah, NJ/London, UK, 2007.

[12] M. P. Driscoll, Psychology of Learning for Instruction, Allyn \& Bacon, Boston, MA, USA, 2 edition, 2000.

[13] B. Zimmerman and D. Schunk, Self-regulated Learning and Academic Achievement: Theoretical Perspectives, Lawrence Erlbaum Associates, Mahwah, NJ, USA, 2001.

[14] L. Hays and K. Handler, "Good design is universal: using universal design principles to promote self-regulated learning in learning management systems when teaching information literacy," Journal of Library \& Information Services in Distance Learning, vol. 14, no. 2, pp. 127-140, 2020.

[15] C. Lai and M. Gu, "Self-regulated out-of-class language learning with technology," Computer Assisted Language Learning, vol. 24, no. 4, pp. 317-335, 2011.

[16] D. H. Schunk, P. Pintrich, and J. L. Meece, Motivation in Education: Theory, Research and Applications, Pearson Prentice Hall, Hoboken, NJ, USA, 2008.

[17] B. L. Leaver, "Self-regulation and learner autonomy," in Achieving Success in Second Language Acquisition, M. Ehrman and B. Shekhtman, Eds., Cambridge University Press, Cambridge, MA, USA, 2009.

[18] T. J. Cleary, G. L. Callan, and B. J. Zimmerman, “Assessing self-regulation as a cyclical, context-specific phenomenon: overview and analysis of SRL microanalytic protocols," $E d-$ ucational Research International, vol. 2012, Article ID 428639, 19 pages, 2012.

[19] T. J. Cleary, G. L. Callan, J. Malatesta, and T. Adams, "Examining the level of convergence among self-regulated learning microanalytic processes, achievement, and a selfreport questionnaire," Journal of Psychoeducational Assessment, vol. 33, no. 5, pp. 439-450, 2015.

[20] G. Kermarrec, G. Regaieg, and R. Clayton, "Mixed-methods approaches to learning strategies and self-regulation in Physical Education: a literature review," Physical Education and Sport Pedagogy, 2021, In press.

[21] C. J. Miller and M. L. Bernacki, "Training preparatory mathematics students to be high ability self-regulators: comparative and case-study analyses of impact on learning behavior and achievement," High Ability Studies, vol. 30, no. 1-2, pp. 167-197, 2019.

[22] R. Oxford, Language Learning Strategies: What Every Teacher Should Know, , Newbury House, Rowley, MA, USA, 1990pp. 284-297, '.

[23] A. Wenden and J. Rubin, Learner Strategies in Language Learning, Prentice-Hall, Englewood Cliffs, NJ, USA, 1987.

[24] L. Bol and J. K. Garner, "Challenges in supporting self-regulation in distance education environments," Journal of Computing in Higher Education, vol. 23, no. 2-3, pp. 104-123, 2011.

[25] K. Lodewyk, P. Winne, and D. Jamieson-Noel, "Implications of task structure on self-regulated learning and achievement," Educational Psychology, vol. 9, no. 1, pp. 1-25, 2009.

[26] W. Wu, Y. Hsu, Q. Yang, C. Jiang-Jie, and M. S. Y. Jong, "Effects of the self-regulated strategy within the context of spherical video-based virtual reality on students' learning performances in an art history class," Interactive Learning Environments, 2021, In press.

[27] B. J. Zimmerman, "Goal setting: a key proactive source of academic self-regulation," in Motivation and Self-Regulated Learning: Theory, Research, and Applications, D. H. Schunk and B. J. Zimmerman, Eds., Lawrence Erlbaum, New York, NY, USA, 2008.
[28] J. Malmberg, S. Järvelä, and P. Kirschner, "Elementary school students' strategic learning: does task-type matter?” Metacognition and Learning, vol. 9, no. 2, pp. 113-136, 2014.

[29] A. Kaplan and E. Lichtinger, "Achievement goal orientations and self-regulation in writing: an integrative perspective," Journal of Educational Psychology, vol. 101, no. 1, pp. 51-69, 2009.

[30] J. M. Harackiewicz, K. E. Barron, J. M. Tauer, S. M. Carter, and A. J. Elliot, "Short-term and long-term consequences of achievement goals: predicting interest and performance over time," Journal of Educational Psychology, vol. 92, no. 2, pp. 316-330, 2000.

[31] A. U. Chamot, "Issues in language learning strategy research and teaching," Electronic Journal of Foreign Language Teaching, vol. 1, no. 1, pp. 14-26, 2004.

[32] A. Cohen and E. Macaro, Language Learning Strategies: 30 Years of Research and Practice, Oxford University Press, Oxford, UK, 2007.

[33] Z. Dörnyei, Motivational Strategies in Language Classroom, Cambridge University Press, Cambridge, MA, USA, 2001.

[34] J. Broadbent, "Comparing online and blended learner"s selfregulated learning strategies and academic performance," The Internet and Higher Education, vol. 33, pp. 24-32, 2017.

[35] R. Garcia, K. Falkner, and R. Vivian, "Systematic literature review: self-Regulated Learning strategies using e-learning tools for Computer Science," Computers \& Education, vol. 123, pp. 150-163, 2018.

[36] E. A. Locke and G. P. Latham, A Theory of Goal Setting and Task Performance, Prentice-Hall, Englewood Cliffs, NJ, USA, 1990.

[37] C. B. McCormick and M. Pressley, Educational Psychology: Learning, Instruction, Assessment, Longman Publishing/ Addison Wesley L, Harlow, UK, 1997.

[38] B. J. Zimmerman, "Becoming a self-regulated learner: an overview," Theory into Practice, vol. 41, no. 2, pp. 64-70, 2002.

[39] A. Kitsantas, "Test preparation and performance: a self-regulatory analysis," The Journal of Experimental Education, vol. 70, pp. 101-113, 2002.

[40] R. F. Baumeister and K. D. Vohs, Eds., Handbook of SelfRegulation: Research, Theory, and Applications, Guilford Press, New York, NY, USA, 2004.

[41] R. Janoff-Bulman and P. Brickman, "Expectations and what people learn from failure," in Expectations and Actions: Expectancy-Value Models in Psychology, N. T. Feather, Ed., pp. 207-237, Erlbaum, Hillsdale, NJ, USA, 1982.

[42] G. Maruyama, R. A. Rubin, and G. G. Kingsbury, "Self-esteem and educational achievement: independent constructs with a common cause?" Journal of Personality and Social Psychology, vol. 40, pp. 962-975, 1981.

[43] D. B. McFarlin, R. F. Baumeister, and J. Blascovich, "On knowing when to quit: task failure, self-esteem, advice, and nonproductive persistence," Journal of Personality, vol. 52, pp. $138-155,1984$. 